\title{
Decentralization as a Precarious Component of Contemporary European Governance ${ }^{1}$
}

Ivan Koprić

I have been dealing intensively with decentralization and local self-government for two decades now. My interest is both theoretical and practical. In the second part of the 1990s, when I started to deal with local governance, Croatia was a rather centralized country which needed decentralization. At that time, I was engaged in several projects which were intended to produce the professional and policy basis for the decentralization of the country.

However, despite some great achievements at the beginning of the new millennium, further decentralization and possible territorial reorganization are still among the hottest issues of public debate in Croatia. The scientific and professional community, citizens and civil society, the business community and certain minor political parties are in favour of decentralization, while the major parties are in the quite opposing positions. As many others, I am disappointed with this situation.

Because of these reasons, I decided to talk about decentralization on the occasion of being awarded the Alena Brunovska Award for teaching excellence in public administration. The title obviously reflects two inspirations. On the one hand, there is the notion of European governance, which follows from the main theme of this year's NISPAcee conference. On the other hand, there is decentralization, which follows from local democracy as one of my main theoretical, research and policy interests.

I will present several main issues and theses about the interconnectedness of decentralization and European governance in a time of overall complexity and wicked governance problems.

1 Speech on the occasion of being awarded "The Alena Brunovska Award for Teaching Excellence in Public Administration" at the $24^{\text {th }}$ NISPAcee Annual Conference 2016 held in Zagreb, Croatia, May 19-21, 2016.

2 Full Professor of Administrative Science and Head of the Study Centre for Public Administration and Public Finances at the Faculty of Law, University of Zagreb, Croatia; President of the Institute of Public Administration, Zagreb, Croatia. 


\section{Local government function in the environment, which imposes too many challenges}

The challenges of contemporary societies and public governance are more and more frequently called "wicked problems". The main characteristics of the environment in which local governments have to function are complexity, dynamics and nonlinearity. Because of that, the situation and its development are hardly predictable for local governments. Just to mention local consequences of massive migrations, pollution or natural disasters, such as floods. There are many new actors that play significant roles in society, many of whom use various, competitive and - occasionally - aggressive strategies. Some of them want to take over the functions and certain roles which traditionally belonged to the local self-government. The consequences may be far-reaching.

In such circumstances, local governments can no longer employ strategies such as traditional administration of particular local tasks, old-fashioned management of local utilities and slow distillation of local interest into locally important political decisions. They have to have the capacity for quick reactions to sudden stressful events which may cause long-term and profound consequences not only on their respective territories, but also in the broader areas.

\section{After being one of the core values of the democratic political system, decentralization is becoming an instrument for solving problems}

Although local self-government has for decades been treated as a value per se, as an important component of democratic political system, its role is becoming increasingly instrumental. Thus, we can distinguish between old and new types of decentralization. I am fully aware of many serious arguments in older literature against local government. However, the majority of authors saw local self-government as the institution which enhances the democratic state and substantially adds to people's democratic political education. Such a standpoint was defended more passionately than today by great authors like John Stuart Mill, Alexis de Tocqueville and many others.

Further, local units have not got the same role and have not been treated in the same manner in different European models of local self-government. In Europe, we also have local traditions which give municipalities such instrumental tasks as administrative services (issuing documents or licenses) or social-service delivery.

However, substantial change of perception is connected with the New Public Management doctrine. It has not been fully successful in imposing many new management techniques or the techniques borrowed from the private sector, but it has influenced the discourse not only of scholars, but even more notably that of practi- 
tioners and politicians. Because of that, we are influenced and infected by the NPM categories, concepts and way of thinking about the whole public sector, including local self-government.

\section{Considerations related to economy, service delivery, and economic and social development at the local level are overturning considerations about public governance, social solidarity and ecology in local units}

Cost-effectiveness and efficiency, performance management and overall policy success are the basic concepts today. A large number of evaluation studies about local service delivery have been produced. Local governments are supposed to fulfil not only their traditional democratization, administrative and social roles, but also a new, developmental role. Managerial reforms have emphasized the economic impacts of local governments: local politics, local public services, everything local has its price. Value for money, financial and other resources and their usage, budgeting, savings, rationalization, etc. are but some new and relevant issues. Economic crisis in the major part of Europe, along with the European sovereign debt crisis have put a heavy weight on the shoulders of many municipalities.

In times of economic crisis, it is important for local self-governments to create an attractive investment environment and to boost economic development on the local level. Consequently, a range of managerial techniques, such as strategic planning, city marketing (branding), local entrepreneurship, public-private partnership, encouragement of competition between local units etc., have found their place in the development of cities. Therefore, themes such as urban, rural and regional development are inevitable and have to be taken into account when researching contemporary local government systems. Although the problems of public governance, legitimacy, solidarity and ecology are not suppressed by the considerations about economy and savings, in the bulk of the current literature they are not as prominent as one might expect.

\section{Privatization may diminish the role of local governments and reduce the quality of services}

Privatization has become one of the fancy words. Some authors take it as a panacea, a cure for all public-sector diseases. The private sector has been advocating for better efficiency, more rationality and cheaper provision of services. European policy with regard to the services of general economic interest reflects on several services that were traditionally considered part of the local public sector, such as water and energy supply, waste collection and treatment, transport, and many others. The local scope of affairs has been strongly affected and shrunk by this EU policy. Even in 
so-called non-economic, non-commercial services of general interest, such as welfare care, health, education and similar fields, privatization is an important issue in many European countries. Despite some positive impacts, privatization may cause problems with the standards, quality, access to and affordability of services.

However, in its main documents adopted at the end of the 2000s, the Lisbon Treaty with the additional protocols, especially Protocol no. 2 and Protocol no. 26, the EU guaranteed the subsidiarity principle and recognized the essential role and the wide discretion not only of national, but also of regional and local authorities in providing, commissioning and organizing services of general economic interest as closely as possible to the needs of the users. Along with certain examples from various countries, that motivated some authors to coin a new word, re-municipalization, in order to indicate the reverse trend, the trend of regaining control over local services delivery by local governments.

Unfortunately, during the last few years we have been unable to confirm the re-municipalization trend in most parts of Europe. What is clear from empirical insights is that privatization undoubtedly diminishes the role and discretion of local governments.

\section{Local governance and internal decentralization are becoming much more important than the traditional balance with the central governments}

Traditionally, local self-government was seen as the form of vertical division of power by which the central state authorities were limited and the competencies of local councils and other local bodies affirmed. The relations between the central state and the local government were the main axes around which various issues and institutions were conceptualized, legally regulated and designed. Among them one can mention the general clause for the delimitation of municipal powers and tasks, state supervision over local governments, legal protection of the right to local selfgovernment, local share of public revenues, calibration of the local authority to levy the taxes and many other institutions for balancing central-local relations.

The internal dimension has become more and more important in parallel with focusing on good local governance. We may call it internal decentralization, with a decreasing importance of the hierarchical type of governance. The introduction of directly elected mayors, the representation of minorities and independents in local councils, the establishment of youth councils and local partnerships, ensuring wide participation of citizens by local meetings and hearings, recall procedures, referenda, petitions, e-democracy, local civil society, local media, openness, local transparency, freedom of information and integrity of local officials are among the new or refreshed medicaments for healing local democracy and boosting the legitimacy of local institutions. 


\section{Sharp central-local interplay is becoming a more complex game of European multi-level governance}

In comparison to the traditional dichotomy between central and local governments, there is a constantly evolving tendency towards multi-level governance. The majority of European countries have more than one subnational territorial level standing in a relation of mutual dependence, cooperation, competition, impact and control with national and EU authorities. An important role in the governance processes in Europe, in addition to local, national and European levels, belongs to regional governments and sub-municipal units (neighbourhoods, territorial committees, districts, etc.).

The policy of subsidiarity and decentralization promoted by the EU and the Council of Europe contributes to the tendency of regionalization in Europe. EU regional and cohesion policies are directed at strengthening economic, social and territorial cohesion throughout Europe. The role of the sub-municipal level is especially important in large, consolidated local governments and in big cities. Submunicipal units also play a significant role in integrated urban governance.

In such a way, there is a new governance picture in all of Europe: the $E U$ level - national level - regional level - local level - sub-municipal level. Within this new, complex architecture each level has its importance and role. There are many cooperation arrangements, including European territorial cooperation, in which all governance levels may cooperate horizontally and laterally regardless of national borders.

However, in such a multi-level world of governance, the importance of decentralization to basic local authorities and widening local discretion is decreasing. Overall governance counts, local governance counts only as a part of the wider, multi-level picture. Multi-level governance is blurring the traditional central-local dichotomy and reducing the importance of basic local level.

\section{Researching decentralization has to refocus from structures and institutions to outcomes and impacts}

There is a task for all of us who are dealing with decentralization and local democracy to answer the question about the harmonization of local governance in Europe. Is the European harmonization of local government systems a myth or the reality?

There is a huge effort of the $\mathrm{CoE}$ and the EU to promote common standards of local autonomy throughout Europe. Because of the exchange of best practices, the conditionality policy of the EU and intensive mutual learning processes, differences between traditional models of local self-government have been diminishing. 
In spite of the observed harmonization trend, there are still significant differences between them. It seems that local government systems differ especially in territorial organization and average size of local units, local finances, relations between political and executive bodies, state supervision and many other structural and institutional issues.

Because of that, if we wish to get better, more refined results about decentralization in the contemporary European governance frame, I propose to focus on results, outcomes and impacts of local governments as well as on outcomes and impacts of decentralization processes and reforms, rather than on reform designs, structures and institutions. I think this may be more scientifically productive than following and analyzing only basic structural and normative changes.

\section{We have to accept a more practical view on decentralization, in which the core question is management of decentralization, i.e. management of local governance reforms (decentralization in practice)}

What does everything I have said mean for decentralization in practice? Which policy implications does it have? I would say many of them, but for this occasion I must stress improvements in the management of decentralization, because those who are in charge of implementing decentralization reforms have to be aware of the described complexity and non-linearity in contemporary European context. Their approach has to be systemic and evidence-based.

A systemic decentralization process comprises detailed planning, experimentation, legal regulation, formation (reformation) of the various segments of local self-government, monitoring, evaluation and corrections of the decentralization process. The mentioned segments of local self-government systems relate to local authorities and competences, financial autonomy, administrative capacity, political legitimacy, central-local relations and the change of territorial structure. The analysis of achieved results is important for the evaluation, possible corrections and adjustments of the processes of decentralization as well as for the identification of good practices suitable for mutual exchange and learning.

\section{We need to rethink the very definition of decentralization (decentralization in theory)}

We have to ask "What does decentralization mean today, for us, the European citizens?" We need to refine our theoretical approaches and views on decentralization. A massive comparison of decentralization efforts and their consequences has to be undertaken. We have to research all five main roles of local self-government: the administrative, political, social, economic and ecological roles. We need a new 
theory of decentralization which would incorporate our particular European circumstances and experiences.

Is there a new, common European model of local governance or local democracy? Moreover: what does the current European model of governance mean for local self-government, local democracy and local service delivery? Is decentralization endangered by the European multi-level model? Will local authorities be able to use contemporary risks as challenges and transform problems into innovative solutions?

Answering these questions is our common future task; I do not have the ambition to offer the answers in this short presentation, but I do hope I have motivated you to think about them even harder than before.

The European dimension must not be neglected when thinking about decentralization, because the multi-level environment of the enlarged European Union and the huge efforts of the Council of Europe in the field of local, regional, and urban governance will probably have an even stronger influence in the future.

At the end, I wish to thank the Award Committee and my colleagues from the Faculty of Law in Zagreb who nominated me for the Alena Brunovska Award.

Thank you.

Zagreb, 19 May 2016 